Research paper

\title{
Changing importances of professional practice competencies over an engineering career
}

\author{
Dirk J. Pons ${ }^{1}$ \\ ${ }^{1}$ Author to whom correspondence should be addressed Department of Mechanical Engineering, University of Canterbury, \\ Private Bag 4800, Christchurch 8020, New Zealand, Email: dirk.pons@canterbury.ac.nz Tel.: +64 3364 2987; Fax: +64 3364 \\ 2078.
}

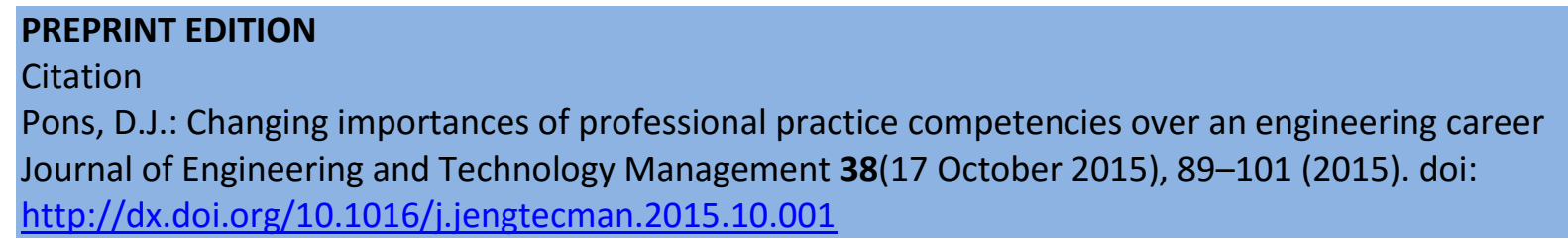

\begin{abstract}
short (100 words)
The profession depends on its practitioners developing management and leadership skills to achieve good client outcomes and robust, reliable products or services, delivered by profitable, ethically run engineering businesses. The difficulty is determining what those skills are, and where in the career they are needed. The New Zealand population of professional engineers was surveyed to rate the importance of a list of management and leadership topics. Results show the relative importance of various topics and how their importance is perceived differently with years of experience. The results also help differentiate the roles of teaching institutions and ongoing in-career professional development.
\end{abstract}

\begin{abstract}
long
Problem- The profession depends on its practitioners developing management and leadership skills to achieve good client outcomes and robust, reliable products or services, delivered by profitable, ethically run engineering businesses. The difficulty is determining what those skills are, and where in the career they are needed. Approach -The New Zealand population of professional engineers was surveyed to rate the importance of a list of management and leadership topics. Findings- Results show the relative importance of various topics and how their importance is perceived differently with years of experience. The rated importance of most engineering management topics becomes significantly higher as the engineer's years of experience lengthen. The areas of largest gap, where the mature engineers assess a topic as significantly more important than the starting engineers include: communication; business processes; change management; contracts; accounting; ethics, law, health and safety. Implications - The results differentiate the roles of teaching institutions and ongoing in-career professional development via human resource managers and providers of professional development training. Results show that mid-career engineers are often significantly less appreciative of engineering management topics than mature engineers. Originality - The size of the survey data permits high statistical power of analysis into the topics of engineering management as perceived by practising professionals in their career phases.
\end{abstract}




\section{$1 \quad$ Introduction}

It is expected that engineers will use engineering management and leadership tools more extensively as their career progresses, and some become specialised management engineers (IPENZ, 2015). Their careers start by taking responsibility for the management of their own personal work and the professionalism thereof, to become independent practitioners. With time they typically take responsibility for managing the work of others in projects and organisations, to become technology or team leaders. Some may stop there, but many other engineers subsequently take responsibilities for managing whole business units or organisations, leading staff, and perhaps eventually for governance and setting strategic direction. Consequently there is a need for engineers to develop an evolving set of professional skills as their career develops. But what exactly are those skills and when are they needed? This question is also relevant to the need for life-long learning and enduring professional development (IEM, 2009).

This is addressed by analysing a large survey-data set to determine the relative importance of management and leadership topics for engineers at different stages in their careers. The particular area of focus for this research was the New Zealand (NZ) engineering profession. In the present context we do not make a firm differentiation between 'management' and 'leadership', but instead simply use the term 'engineering management' to refer to the general set of skills required for organisational success. This was done as there is no consensus in the literature, in either the business or engineering literature, on the boundary between 'management' and 'leadership', so any distinction is necessarily subjective. Furthermore, the topic is generally known within the engineering profession as 'engineering management' and tacitly assumed to include some leadership components, which is another reason to stay with the existing terminology.

\section{Background}

\section{Research question}

The engineering profession is highly dependent on its practitioners developing the necessary management skills to achieve good client outcomes and robust, reliable products or services, delivered by motivated staff in profitable, ethically run engineering businesses. The difficulty is determining what those skills are, when they are needed, and developing the appropriate competencies in graduates and practitioners. The question addressed here is the longitudinal one: what are the various management and leadership capabilities [topics] used in professional engineering practice, where in the engineer's career does the need arise for each? This is an important question because of the implications for teaching and professional development. This question is somewhat related to that asked by Giegold, 'what is the most effective way for an engineering manager to improve his or her leadership skills?'(Giegold, 1981). If it were known how the need arose longitudinally over time, educators, employers, and professional bodies could present the material at an appropriate time and contextualise it accordingly. This could also help differentiate the roles of teaching institutions and ongoing professional development (PD) in-career. Thus some topics might best be taught as part of an undergraduate training, and others as part of a PD programme after graduation: at present that distinction is unknown.

\section{Relevant literature}

That engineers need to know some management and leadership is beyond doubt. The ambiguity is in what exactly they need to know, and where in their career. The first question is what soft-skills engineers need to know. There is some consensus on the composition of that body of knowledge, though it lacks specificity to be really useful. The engineering accords (IEM, 2009) provide guidance, though not at the level of detail for curriculum design (Banik, 2008). 


\section{Management and Leadership}

The notion of 'management' and 'leadership' is generally understood in the management literature to be somewhat overlapped (Simonet \& Tett, 2013). The modern concept of 'leadership' is inextricably linked to strategising, and the two are co-dependent: if there was no strategy to develop then the need for a leader would be diminished. Consequently, organisational change is also usually perceived as a systematic and top-down process (Balogun \& Hailey, 2004; Burnes, 2005) of decisionmaking and deployment, at least from the 'leadership' perspective. The general opinion is that strategy formation is a systematic process and that it is necessarily performed by a leader. The 'directed' approach to strategy development, which is the historical perspective, sees change as the deliberate alignment of the organisation to strategy decided by the leaders direction (Kaplan \& Norton, 1992). Thus the directed approach asserts that strategy should be a deliberately planned response to fit ('align') the organisation to the external environment (Johnson \& Scholes, 2002; NIST, 2013), and that change is the deployment of this strategy. That perspective emphasises a top-down process, and elevates the role of leadership by an upper echelon in decision making (Cannella Jr, 2001). Within the management literature it is sometimes called a 'planned' approach (Burnes, 2005)(p74). Some even call it a 'designed' approach (Johnson \& Scholes, 2002) (p39), which refers to the deliberate and methodical nature of the process (Graetz, Rimmer, Lawrence, \& Smith, 2006) (p10). So one way that management and leadership are differentiated is to state that leadership involves the identification of external alignment needs and opportunities for the organisation, the formation of a vision of the future state of the organisation, the development of a set of strategic actions to achieve that desirable future state, and the internal change management actions that are necessary to develop the underpinning organisational capacity. In contrast the role of managers is to attend to the operational processes concerning the means by which the organisation achieves its purpose or mission, and this involves supervising the allocation of resources (people, consumables, assets, finances). Consequently leadership and management require different skills.

Another perspective, which overlaps somewhat with the previous, is that leadership is primarily about motivating others to change their behaviour to achieve a better outcome, whereas management is about the supervision of resources. From this view anyone can be a leader, and the attribute exists throughout an organisation. The primary leader is then the chief executive officer. These theories assign primary causation for organisation success to the skills and personality of the leader, hence styles of leadership are important (Dulewicz \& Higgs, 2005). Theories include charismatic leadership (Conger \& Kanungo, 1987, 1994, 1997; Conger, Kanungo, \& Menon, 2000), vision, transformational leadership (Robbins, Millett, Cacioppe, \& Waters-Marsh, 2001) (p421), servant leadership (Chewning, 2000; Crippen, 2005; Fisher Jr., 2004; Giampetro-Meyer, Brown, Browne, \& Kubasek, 1998; Greenleaf, 2002) and strategic leadership (Johnson \& Scholes, 2002), among other theories. In these theories leadership is an affective (emotional) process that is directed towards achieving specific behaviours in others, not so much by force of authority as by changing motivation. This too links into change management, as in the previous visioning perspective of leadership, and indeed these various theories are complementary.

These different constructs for leadership and management are found in the psychologymanagement fields, and the engineering literature itself does not generally go to these levels of detail. By examination of what other people consider to be 'engineering management' (as shown below) it is apparent that (a) a wide variety of leadership and management topics are considered to be included, and (b) there is a large amount of variability in what each source considers to be part of the cannon. In addition there is the need to include professional practice matters, of which 'ethics' is the most obvious. 


\section{Engineering management topics in the literature}

A candidate list of engineering management topics therefore necessarily includes leadership, management, and professional practice topics. There is no single comprehensive list in the literature, but it is possible to aggregate the various topics identified in the literature. For this purpose the following list was assembled from these sources (ASME, 2010; Baughman, Brumm, \& Mickelson, 2014; Becerra-Fernandez, Lee, \& Hopkins, 1998; Beruvides \& James, 1997; Bowen, Ganjeizadah, Motavalli, \& Zong, 2005; Farr \& Bowman, 1999; Furterer et al., 2006; Horwitch \& Stohr, 2012; IEM, 2009; Joshi, 2004; Ladd, Holt, \& Rumsey, 2001; Lewis Jr \& Kauffmann, 2002; Mallick \& Chaudhury, 2000; Merino, 2000a, 2000b; Meyers, Fentiman, \& Britton, 1993; Mingers, 1991; Raine, 1996; Sun, Yam, \& Venuvinod, 1999, p 182; Waks \& Frank, 2000; Williamson, Lounsbury, \& Han, 2013). The topics that are generally considered for inclusion are the following, though it should be noted that few if any teaching programmes actually cover them all:

- accounting,

- change management,

- communication,

- conflict,

- contracts,

- cultural,

- decision-making,

- engineering economics,

- environment \& sustainability,

- ethics,

- finance,

- health \& safety,

- human resources,

- intellectual property,

- law,

- leadership,

- legal,

- liability,

- market research,

- marketing and advertising,

- multidisciplinary teams,

- organisational structures,

- procurement,

- product manufacturability,

- project management,

- quality,

- risk management,

- scheduling,

- societal responsibilities,

- standards,

- strategic planning,

- supply chain,

- teamwork,

- vision

While this list may seem impressively detailed, it is worth noting that most of the entries are based on opinions expressed in the literature, and are conjectures rather than evidence-based.

Furthermore the reasons for advocating for certain topics are seldom, if ever, given. There are many 
conjectures in this area but little actual research, neither theoretical and especially not empirical, so the recommendations have to be considered carefully. Also, as already noted, undergraduate programmes seldom if ever include all of these topics, so this begs another question: what is the relative importance of these topics and if teaching time is limited, as is usually the case, then which are most important? A further question logically also follows: what level of skills is required to be developed in students or practitioners in each of these topics, i.e. what are the learning outcomes or graduate capabilities (IEM, 2009)? It would be fair to say that the curricula of most undergraduate engineering management courses have an ad-hoc design. There are just too many things to know, and not enough time in an undergraduate first degree to cover them all, at least not to a depth that will satisfy everyone. Undergraduate programmes tend to select a basket of the above skills to teach. Some things are left for the engineer to learn on the job after graduation, but the precise mix is variable between engineering programmes. Nor is there any systematic way for course designers to make this partition.

This raises the question of timing. Where in their careers do engineers need the EM knowledge? At the early stages of an engineer's career the nature of the work, and therefore the EM skills required, appear to be primarily in project management or team leader roles, progressing to technical manager, and subsequently general manager (Pons \& Raine, 2014). This at least is how the profession perceives the career path (IPENZ, 2009). There is a general expansion of responsibilities, including a growing responsibility for others and the organisation. The research literature itself is silent on the question of where in their careers engineers need the EM knowledge. There do not appear to be any empirical studies whatsoever that have addressed this timing question. It is an important question, because so much of the engineer's ongoing professional development is left to the employment phase of the career. Indeed the Accord specifically expects that engineers will embrace life-long learning (IEM, 2009).

To sum up, the key questions from the perspectives of curriculum design and professional development are: What are the various management and leadership capabilities [topics] used in professional engineering practice. Where in the engineer's career does the need arise for each? It will be noted that these questions comprise cross-sectional and longitudinal elements.

\section{$3 \quad$ Methodology}

The purpose of this work was to determine the changing use of various engineering management and leadership topics over career progression. There was no specific starting hypothesis, other than an expectation that the use might change over time, and designed the study accordingly. The approach was to survey the whole New Zealand population of professional engineers, namely those who were members of the Institute of Professional Engineers NZ (IPENZ). This is the primary professional body for NZ and includes all practice areas. The Institute sends out an annual salary survey to all its members, and in 2009 two questions were added on engineering management:

- Q17 To what extent does your current role involve engineering management? Response categories: -1 = Did not answer; 1=Very Great Extent; 2=Great Extent; 3=Moderate Extent; 4=Slight Extent; $5=$ Not at all; $6=$ Do not know or not applicable

- Q18 In your opinion, what engineering management topics (if any) should be taught to undergraduates? (Select as many as apply)

A list of topics was provided, see Appendix A. The list includes both management and leadership activities, and did not specifically differentiate between the two when asking the questions. The list was derived from the Washington accord graduate competencies and the literature for the engineering management curriculum.

Other standard questions were also asked: qualification, years since graduation, practice area, job points, and demographics. Job points is an IPENZ measure of job complexity and is determined by 
aggregating responses to several questions. Included therein are questions about the level of responsibility for decision-making by the engineer. It therefore broadly measures complexity in professional practice, and is known to correlate with remuneration. The number of responses received was 2276 , representing a $38 \%$ return. The population was all the professionally active IPENZ Graduate Members, Professional Members, Technical Members, Associate Members and Fellows who were living in NZ and still professionally active. Ethics approval was obtained from the University of Canterbury and permission from IPENZ.

The survey data were analysed to extract (a) summaries of frequencies, (b) association rules, and (c) ANOVA was applied to compare the proportions of responses. The software tool used was Statistica ${ }^{\circledR}$. Association rules analysis (ARA) provides the opportunity to explore the data and seek out hidden relationships in a posterior manner. The method, though commonly used for marketing analysis, is an uncommon research method. There are no known instances of it being applied in the present field and therefore a brief description is provided in Appendix B.

\section{$4 \quad$ Results}

\subsection{Importance of engineering management changes over career}

Several measures for career progression are available. The first is membership category (graduate, member, certified professional, fellow, etc.). However there are issues with this categorisation, particularly as some engineers are remaining for decades in the 'graduate' category and not progressing to full membership. A second measure is job points. Job points is an IPENZ measure of job complexity and is determined by aggregating responses to several questions. Included therein are questions about the level of responsibility for decision-making by the engineer. It broadly measures complexity in professional practice. The survey included the measure of job points, and the analysis did show an increased use of engineering management with advancing job points. The third measure is years since graduation, i.e. a time-experience variable. There was also an increased use of engineering management with this variable, though less marked than for job points.

Respondents were categorised into three groups depending on their involvement with engineering management at Q17: low ('slight extent' and 'not at all'); moderate ('moderate extent); high ('great extent' and 'very great extent'). This grouping is highly predictive of job points score, as shown in Figure 1.

The implications of this are that involvement with engineering management reasonably accurately predicts job points, and that in turn is known to be linked to remuneration. The corollary is that those engineers who wish to advance in promotion and salary will probably need to develop the capability to be involved with engineering management. By implication they will need to direct their professional development into these areas. The profiles of the three categories were determined with ARA, see Figure 2.

ARA is a data-mining method that is used for qualitative data. It does not assume any prior distribution of results, nor does it require prior hypotheses. Instead it trawls through large data-sets seeking whatever associations may exist, whether or not the research has identified them beforehand. The statistical algorithm within ARA searches for co-occurrence of certain responses (items) with other responses. The output are rules with the structure if 'body' then likely 'head', where the body and head are items in the responses. The rules may be represented as tables or graphically. It is similar to ANOVA in seeking statistically significant association, though with qualitative variables. Consequently it only identifies the more statistically important associations. This means that just because some response seems prominent in the frequencies, does not necessarily mean that it will meet the criteria for being a significant association. The associations show the co-occurrence of responses, not the absolute frequency of individual responses. 
The two main measures of statistical significance for this method are support and confidence. Support is the joint probability (relative frequency of co-occurrence) of items within the variables, i.e., separately for the Body and Head of each association rule. Thus support \% of the time people who replied body also replied head. Or to put it another way, there is a support \% chance of cooccurrence of body and head. Confidence Value is the conditional probability of the Head of the association rule, given the Body of the association rule. Thus for those who responded body there was a Confidence Value \% chance that they also replied head. Or, for those who were body, there was a confidence $\%$ chance of them responding/doing head. Or there is a confidence $\%$ of head for those who had body. ARA identifies the association between variables, not the temporal causality: it cannot prove causality. Nonetheless it can show which variables are grouped together. Note that the strength of the association is not necessarily or even generally the same when the order of variables is reversed, i.e. the associations are asymmetrical. For example, it is possible that people who said $X$ always also said $Y$. However of all those who said $Y$, only a few also said $X$. The inference is that $X$ always needs $Y$, but $Y$ on its own does not need $X$. Thus the strengths of the associations can be used to infer precedence, even if not causality.

In this case the ARA shows that low EM users tend to be graduate members who work in planning \& design. Moderate EM users also work in planning \& design, but tend to be professional members. High EM users tend to be professional members, and are not associated with any one practice area.

\subsection{Perceptions of engineering management over career}

The topic data were then analysed according to three career categories: start (up to 3 yrs experience), middle ( $>3-13$ yrs experience), and mature ( $>13$ yrs experience). These demarcations were selected as other analysis (not shown here) had indicated that the use of engineering management changed at these points. Years of Experience was selected as the measure rather than membership grade or job points, because it shows the temporal progression most directly. Membership grade is not a particularly good measure of maturity of practice, especially with the 'aged graduate' problem. Job points is an attractive measure, and has good correlation, but unfortunately it is a measure local to NZ. Using job points would make the results less comparable and transferrable to other jurisdictions, so the simpler and more universal measure of timeexperience was used instead. The results are shown as ANOVA decompositions in Figure 3 . The data are the proportions of engineers who nominated the topic as important to be taught to undergraduate students. Multiple topics are overlaid on each other, but staggered for readability. For each topic there are three bars, representing the confidence intervals. When the bars for a topic do not overlap, then that tends to show a significant difference. The results are split across three charts as there are too many factors for one.

Each topic has three data points, connected with lines. The data points are the mean proportions of support for that topic, categorised by the career phase (start, middle, mature). Each point has a vertical bar which represents the limits of the $95 \%$ confidence interval. The points for one topic are somewhat laterally offset to those of other topics: this is simply for readability. There are several features to note in the results. The ANOVA lines that are worth greater attention are those that are (1) highest on the page or (2) steepest.

\section{Importance of topics}

Some topics score higher than others. For example communication was selected more often than product certification. Topics that are placed higher on the figure are interpreted as being more important. The top three topics were communication, project planning, and ethics. Note that the 
analysis here does not differentiate between discipline areas. The most important topics for those in the mature professional phase were (in decreasing order of importance): communication; project planning; ethics; project costing; team development; law; contracting; health and safety; business processes; project monitoring; risk management; environmental; net present value (NPV). These all had at least $30 \%$ support from the group of mature engineers.

\section{Consistency of expectations}

In most cases the assessments of the importance of any one topic by the starting, middle and mature engineers were consistent. This was unexpected. For example, all three career groups thought that communication was more important than economics (Figure 3a). There were no major areas where one group thought very differently about a topic. This is a positive feature, and suggests that there is some mechanism that is effectively reconciling expectations. For graduates it may their undergraduate taught courses or holiday work-experience, though the mechanism cannot be precisely identified from the present data. Whatever the mechanisms, it is encouraging to see that starting engineering generally perceive the relative importance of the topics in similar ways to mature engineers. However, this does not mean that the absolute importance was the same, as the next section shows.

\section{Changed importance of EM topics with time}

Most of the ANOVA lines trend slightly upwards. This means that as engineers became older so they felt the topics were more important. Strictly, a greater proportion of mature engineers thought the topic was important than did starting engineers. The implications are that new engineers think the topic is important, but they often do not realise just how important. When the bars for a single topic do not overlap, then that shows a statistically significant difference. Those cases are interpreted as being areas where there is a particularly large gap, generally a deficit, in what the starting engineers think they will need to know. These top priority items are identified as List 1 . The implications are that starting engineers could be better prepared in these areas, or concentrate on developing those skills during ongoing professional development. There were also cases where the differences were not significant (List 2) or the trend was downwards (List 3).

List 1: Cases where the gap in rated importance is particularly large between starting and mature engineers include: communication; business processes; change management; contracts; accounting; ethics, law, health and safety; NPV; innovation; marketing; human resources; project costing; team development; risk management; environmental; quality; project planning; professional membership; project costing; society; strategy.

List 2: Areas where the rated importance between early career and mature engineers was similar or not-statistically important were: budgets; cultural; economics; entrepreneurship; knowledge management; motivation \& leadership; organisational structures; personality; project monitoring.

List 3: Areas where the rated importance decreased with experience included: career planning; product certification; procurement. Starting engineers tended to perceive these as more important than did mature engineers. The reason is unknown. It is possible that starting engineers are uneasy about these topics, initially have low self-efficacy (Bandura, 1997) towards them, but subsequently realise they are less daunting than expected. However that is simply a speculative hypothesis. 


\section{Where in time does the need arise?}

The charts are also useful in another way: they suggest where in the career phase the need arises. This is apparent by inspection of the gradient. For example team development has a line that is initially flat and then rises steeply later. This shows that engineers who are in mid-career do not see the need for team development any more than those starting, but mature engineers do. This implies that it is middle-career engineers that might benefit most from more knowledge in this area, in preparation for future responsibilities. Thus it is suggested that the location of the steepest gradient in the ANOVA line shows where the need arises. This is useful because it permits an approximate allocation of the priorities between university undergraduate-training and in-career professionaldevelopment, at least for some of the items in List 1.

Thus teaching institutions may need to do more regarding: accounting; communication; contracts; ethics; health and safety; law; marketing; net present value; project planning; project costing; risk management; environmental. Naturally the difficulty is that the base level of teaching in these areas is unknown, and that base changes over the years, and will have changed substantially over the 40 yrs since some of these engineers graduated. So the results are more a summary of the history of how these topics have been taught, rather than necessarily a statement of current gaps. Also, these data are for engineering in general, whereas it is actually taught in disciplines, and the relative importance of topics varies greatly with the disciplines. Nonetheless, the list is a starting point where other more specific guidance is unavailable.

Similarly, in-service professional development (after graduation) may need to target: ethics; human resources; law; net present value; project costing; quality; risk management; society; strategy; team development. (There is some overlap with the previous set.) These are all topics that rise in importance during the middle career years. This has implications for human resource managers and providers of professional development courses.

\section{Discussion}

\subsection{Outcomes: What has been achieved?}

This work makes a number of contributions. The first is the provision of an evidence-based approach, this being one of only a few empirical studies into the topics of engineering management as perceived by practising professionals.

A second contribution is that the work identifies which topics of engineering management are important. The most important topics for those in the mature professional phase were (in decreasing order of importance): communication; project planning; ethics; project costing; team development; law; contracting; health and safety; business processes; project monitoring; risk management; environmental; NPV. These all had at least $30 \%$ support from the group of mature engineers. In most cases the assessments of the starting, middle and mature engineers were consistent: starting engineering generally perceive the relative importance of the topics in similar ways to mature engineers.

A third contribution is an elucidation of the changing importance of these topics as career progresses. This has not previously been identified in the literature, at least not from an empirical approach. The results clearly show that the rated importance of most engineering management topics becomes significantly higher as the engineer's years of experience lengthen. The areas of largest gap, where the mature engineers assess a topic as significantly more important than the starting engineers include: communication; business processes; change management; contracts; accounting; ethics, law, health and safety; NPV; innovation; marketing; human resources; project costing; team development; risk management; environmental; quality; project planning; professional membership; project costing; society; strategy. This enables the work to also approximately identify 
where the responsibility lies between undergraduate-training and professional-development, for the various topics. This too is a novel outcome and has the potential to inform the otherwise subjective debate as to the balance of responsibilities between the universities and the profession for the development of an engineer's knowledge and skills. This is also potentially useful for planning professional development courses, as it identifies where engineers might be most responsive to receiving new knowledge.

\subsection{Implications for practitioners}

The implications for engineering practitioners are categorised as follow.

\section{For Students and new graduates}

On the positive side, starting engineering generally perceive the relative importance of the various engineering management topics in similar ways to mature engineers. However, if new engineers think the topic is important, they often do not realise just how important it will become later in a professional career. The areas of largest gap, where the mature engineers assess a topic as significantly more important than the starting engineers include: communication; business processes; change management; contracts; accounting; ethics, law, health and safety; NPV; innovation; marketing; human resources; project costing; team development; risk management; environmental; quality; project planning; professional membership; project costing; society; strategy. The implications are that starting engineers might benefit from being better prepared in these areas, or concentrate on developing those skills during ongoing professional development.

\section{For mid-career practising professional engineers}

Results show that mid-career engineers are often significantly less appreciative of engineering management topics than mature engineers. The tentative implications for this group of engineering practitioners are that they will have to develop and sustain an appreciation for the engineering management topics at mid-career if they are to advance to top positions. It is suggested that they consider actively managing their ongoing professional development if they aspire to top employment positions. Particular areas to be proactive about include communication, contracts, business processes, ethics, law, health \& safety, NPV, project planning, project costing, and team development. It may be worth looking for opportunities to develop knowledge and skills in those areas through work assignments or professional development opportunities.

\section{For teaching institutions}

The results suggest that teaching institutions are generally doing a reasonable job, at least of making graduates aware of the importance of engineering management, though the sufficiency of the learning could not be assessed in this study. However graduates and starting engineers tend to underestimate the importance of certain topics. Teaching institutions may like to consider how they are teaching these topics, particularly how they are being contextualised so that students can understand the importance and reach their full professional potential: accounting; communication; contracts; ethics; health and safety; law; marketing; NPV; project planning; project costing; risk management; environmental. These are the topics from Figure 3 where starting engineers are least aware of the skills that will be needed to move to the middle career stage. These results are for engineering in general, whereas it is more often taught in disciplines, and so the above comments will need to be tempered by discipline requirements.

\section{For professional-development providers}

Human resource managers and providers of professional development training may find it useful to target the following topics: ethics; human resources; law; NPV; project costing; quality; risk management; society; strategy; team development. These are all topics that rise in importance 
during the middle career years. The data showed that engineers in Medium career phases tended to place lower importance on engineering management topics than those who are more advanced in their careers. Those who provide professional development within organisations may encounter passivity from engineering trainees towards some engineering management topics. In which case trainers might like to consider designing their delivery to show the context and explain the importance of the topics. Perhaps mature engineers in these organisations can assist as mentors to encourage the next generation to develop the knowledge and skills in these areas. There is a sizeable group of engineers who progress slowly if at all to full professional membership: we termed these 'aged graduates'. Their involvement in engineering management is significantly less than other members, but their job points are similar. Their reasons for staying, whether choice or circumstances, could not be determined from this dataset, but they conceivably have different professional development needs to other groups.

\subsection{Implications for further research}

A brief discussion of the limitations of the methodology is in order. The methodology was crosssectional in nature, in that the survey was deployed at one point in time- as opposed to a longitudinal design which would have followed individual engineers and conducted many surveys over an extended period of time. While longitudinal surveys are recognised as being among the best quality data, the cross-sectional approach is also useful. In this case there were multiple cross sections, since different engineers were surveyed at different phases in their careers. This permitted insights to be extracted regarding the changing needs of engineers in their careers. This assumes that the changes observed were due to changes in the respondents' needs for professional development, as opposed to fundamental changes in the body of knowledge in question. We submit this is a reasonably robust assumption, because soft-skill topics like 'communication' have not changed markedly in a decade. Hence the growing importance of the topic over a career can be attributed to engineers appreciating its importance more, rather than engineers feeling that the topic itself has significantly changed over the years. However if we had been surveying engineering design methods, e.g. structural engineering, then this would not have been a safe assumption because the underlying body of knowledge has changed markedly over the decades, which of itself could be expected to contribute to respondents' sense of continued importance of the subject deeper into their careers. Therefore, even though a longitudinal design was not used, the crosssectional design probably does provide useful insights into the changing importance over time of the topics included in the survey. It goes without saying that conducting a longitudinal study of the development of engineers' professional practice skills would be a valid and interesting research question. However such studies are difficult to conduct because of the long time dimension, hence also their scarcity.

This research has identified the relative importance of the various engineering management topics, and where the rated need changed in a professional career. However this is for engineering in general, not specific disciplines. Therefore the above implications will need to be adapted when dealing with specific disciplines.

The work did not set out to explore professional development of practising engineers, but it did uncover some effects nonetheless. Apparently professional development is a complex subject that could benefit from further research. Why are mid-career engineers sometimes less appreciative of engineering management? Why do some engineers stay in the 'graduate' category for so long?

Another potential future research question, not addressed by this dataset, is whether the extent to which engineers report using management tools is sufficient for the success of their organisations. In 
other words, are these methods, and their implementation, adding value towards the organisational purpose? One presumes so, but it could be worth checking, and if not then it could suggest new tools are required.

\section{Conclusions}

The research question was to determine where in a professional career the need arises for the various management topics. The answer to this longitudinal type question was teased out from cross-sectional survey data by categorising respondents according to their years of experience (which was known). The results show that there is a significant increase in the importance of most engineering management topics.

While starting engineers assessed the relative importance of various topics consistently with mature engineers, the starting engineers generally did not realise just how important the topics will become later in a professional career. The areas of largest gap, where the mature engineers assess a topic as significantly more important than the starting engineers have been identified. The implications are that starting engineers could be better prepared in these areas, or concentrate on developing those skills during ongoing professional development. The results also help differentiate the roles of teaching institutions and ongoing professional development. Thus topics were identified that need to be considered as part of an undergraduate training, and others as part of a professional development programme after graduation.

\section{Acknowledgements}

The Institution of Professional Engineers New Zealand (IPENZ) is acknowledged for provision of survey data, with particular thanks to Dr Andrew Cleland (CE) and Brett Williams (Director - Learning and Assessment). IPENZ is the professional body which represents professional engineers from all disciplines in New Zealand (www.ipenz.org.nz).

\section{Conflict of interests}

The authors declare no conflict of interest regarding the publication of this paper. The research was conducted without commercial or financial benefit from a third party. There was no third-party influence in the work: its approach, interpretation of data, writing, or submission decisions. There were no external funding bodies involved in this work.

\section{A Appendix: Survey questions}

The survey questions were under the control of IPENZ and were along the following lines.

Q1 What is your Employment Status?

Q2 Do you work In or With Engineering

Q3 What Region do you work in?

Q4 What is your highest Qualification.

Q5 How many years engineering experience do you have?

Q6 How many hours do you work in a week?

Q7 What is your Practice area?

Q8 In which Sector do you work?

Q9 In which Field do you work?

Q10 What is the nature of your Work Activity in that field?

Q11 Did you Start or Change employment in the past year?

Q12 How much Annual Leave do you get? Eng Management

Q13-16 Other questions relating to remuneration which were not released to this research project.

Q17 To what extent does your current role involve engineering management? 
Response categories: -1 = Did not answer; 1=Very Great Extent; 2=Great Extent; 3=Moderate

Extent; $4=$ Slight Extent; $5=$ Not at all; $6=$ Do not know or not applicable

\title{
Q18 In your opinion, what engineering management topics (if any) should be taught to undergraduates? (Select as many as apply, see Table A1)
}

\author{
Q19 Do you hold the professional registration for CPEng? \\ Q20 Do you hold the professional registration for IntPE \\ Q21 Do you hold the professional registration for CertEtn \\ Q22 Do you hold the professional registration for ETPract \\ Q23 Gender \\ Q34 Year of birth \\ Q35 Member Grade \\ Q36 Total job points (JP)
}

\section{B Appendix: Association rules analysis (ARA)}

ARA is a data-mining method that is used for qualitative data. It does not assume any prior distribution of results, nor does it require prior hypotheses. Instead it trawls through large data-sets seeking whatever associations may exist, whether or not the research has identified them beforehand. The statistical algorithm within ARA searches for co-occurrence of certain responses (items) with other responses. The output are rules with the structure if 'body' then likely 'head', where the body and head are items in the responses. The rules may be represented as tables or graphically. It is similar to ANOVA in seeking statistically significant association, though with qualitative variables. Consequently it only identifies the more statistically important associations. This means that just because some response seems prominent in the frequencies, does not necessarily mean that it will meet the criteria for being a significant association. The associations show the co-occurrence of responses, not the absolute frequency of individual responses.

The two main measures of statistical significance for this method are support and confidence. Support is the joint probability (relative frequency of co-occurrence) of items within the variables, i.e., separately for the Body and Head of each association rule. Thus support \% of the time people who replied body also replied head. Or to put it another way, there is a support \% chance of cooccurrence of body and head. Confidence Value is the conditional probability of the Head of the association rule, given the Body of the association rule. Thus for those who responded body there was a Confidence Value \% chance that they also replied head. Or, for those who were body, there was a confidence $\%$ chance of them responding/doing head. Or there is a confidence $\%$ of head for those who had body. ARA identifies the association between variables, not the temporal causality: it cannot prove causality. Nonetheless it can show which variables are grouped together. Note that the strength of the association is not necessarily or even generally the same when the order of variables is reversed, i.e. the associations are asymmetrical. For example, it is possible that people who said $X$ always also said $Y$. However of all those who said $Y$, only a few also said $X$. The inference is that $X$ always needs $Y$, but $Y$ on its own does not need $X$. Thus the strengths of the associations can be used to infer precedence, even if not causality.

\section{Appendix: Tables}

See Table C1 for mean importance of each topic, partitioned into career phase. 


\section{List of figures}

\section{EMUser; LS Means}

Current effect: $F(2,2110)=89.725, p=0.0000$

Effective hypothesis decomposition

Vertical bars denote 0.95 confidence intervals

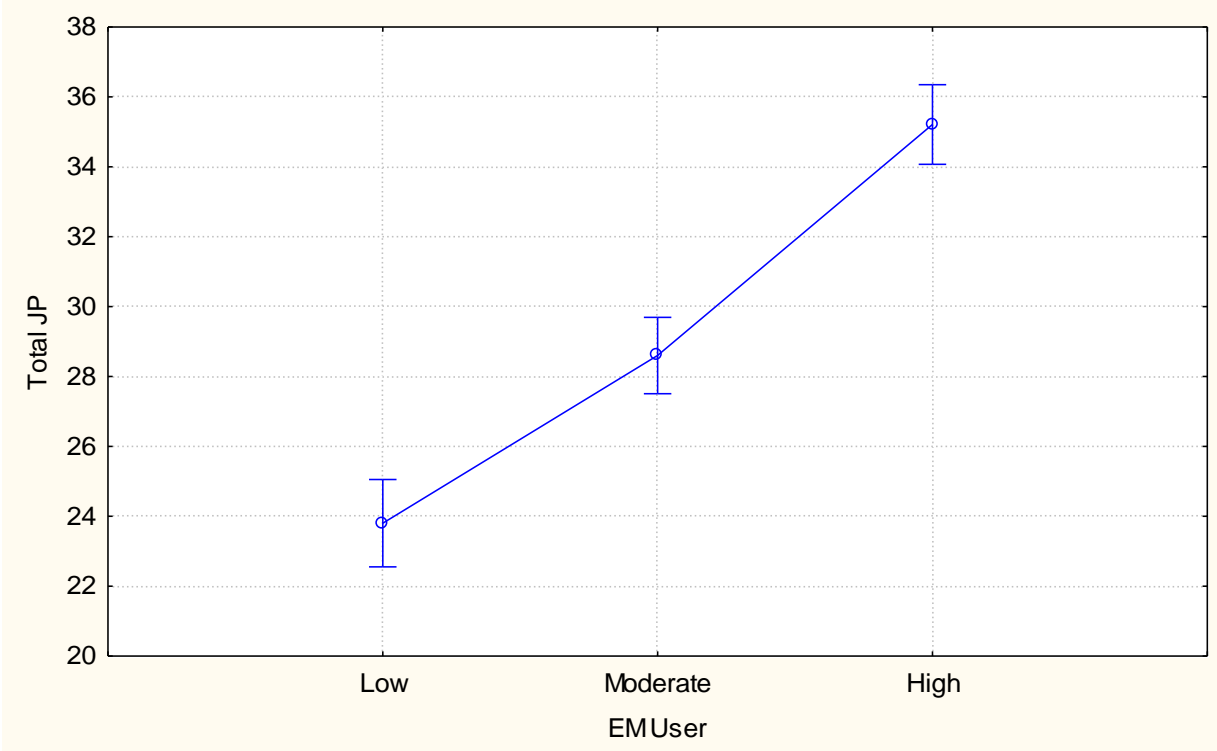

Figure 1: ANOVA decomposition of the job points (JP) score for the simplified three categories of engineering management usage. The results show there is a significant difference in the JP between engineers based on their usage (low-moderate-high) of engineering management. Engineers with higher job points tend to use EM more. 


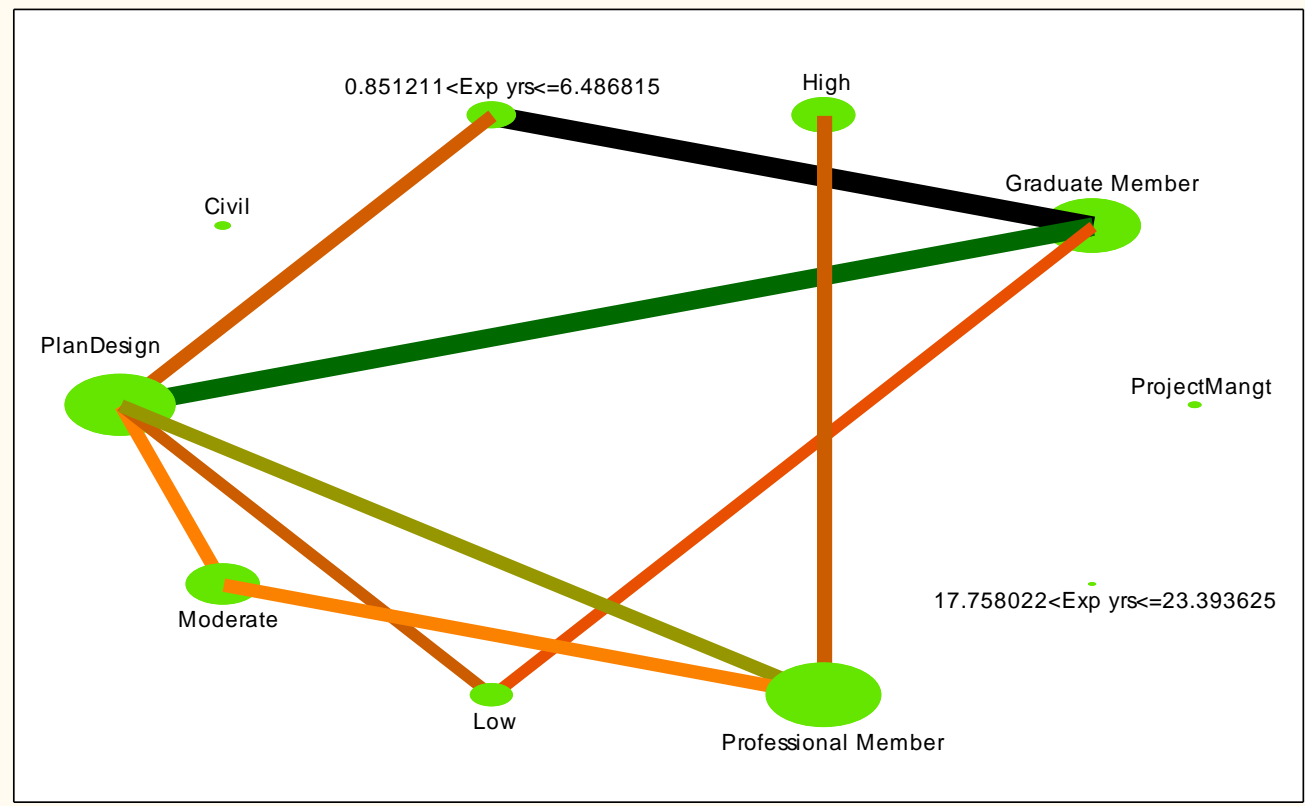

Figure 2: ARA web graph showing the factors associated with the various EM user categories. The larger the nodes (ellipses) the more prevalent that response, the thicker the line the great the joint occurrence of the items, and the darker the line the greater the statistical significance. The variables admitted to this analysis were practice (7), work activity (10), member grade (21), EM user (25), and experience yrs (5). In this case the inferences are: that graduate engineers have between 0.85 and 6.48 years experience (which is unsurprising); that graduates tend to work in Planning \& design; that professional members are associated with Planning and design in particular; that professional members tend to use engineering management to a high extent. 
Career Phase Yrs; LS Means

Wilks lambda $=.86863, F(66,4480)=4.9522, p=0.0000$

Effective hypothesis decomposition

Vertical bars denote 0.95 confidence intervals

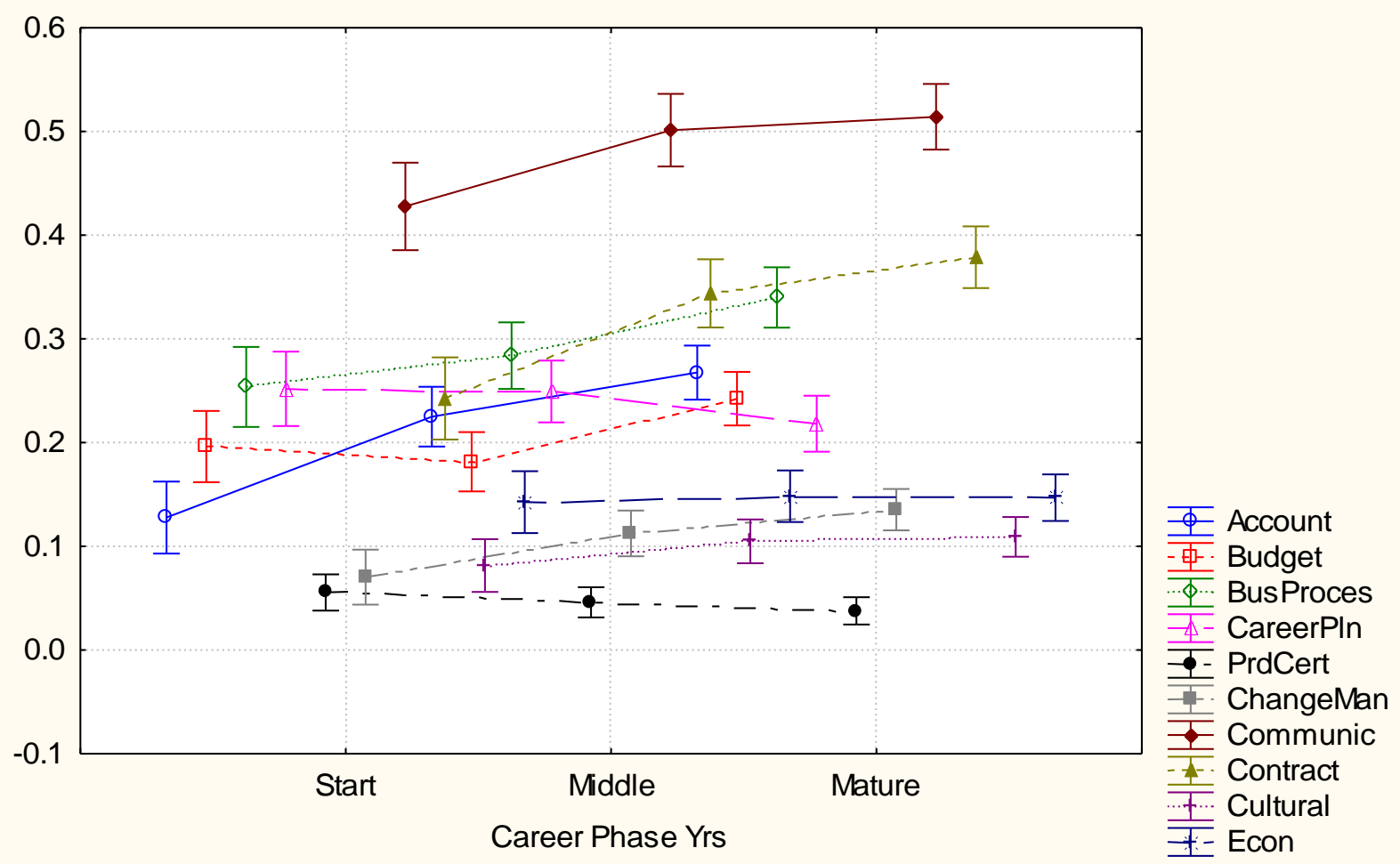

Figure $3 a, b, c$ : ANOVA decompositions for proportional support for various engineering management topics, categorised by years of experience. See Table A1 for full titles of the topics. Each coloured trace represents the importance of one topic (e.g. accountancy) as expressed by engineers at the Start, Middle, or Mature phase of their career. Importance is measured as the proportion of engineers who deemed that topic important. The multiple traces represent the results for the various topics. Note that the traces are offset from the Start, Middle, and Mature vertical lines: this is merely for readability. 
Career Phase Yrs; LS Means

Wilks lambda $=.86863, F(66,4480)=4.9522, p=0.0000$

Effective hypothesis decomposition

Vertical bars denote 0.95 confidence intervals

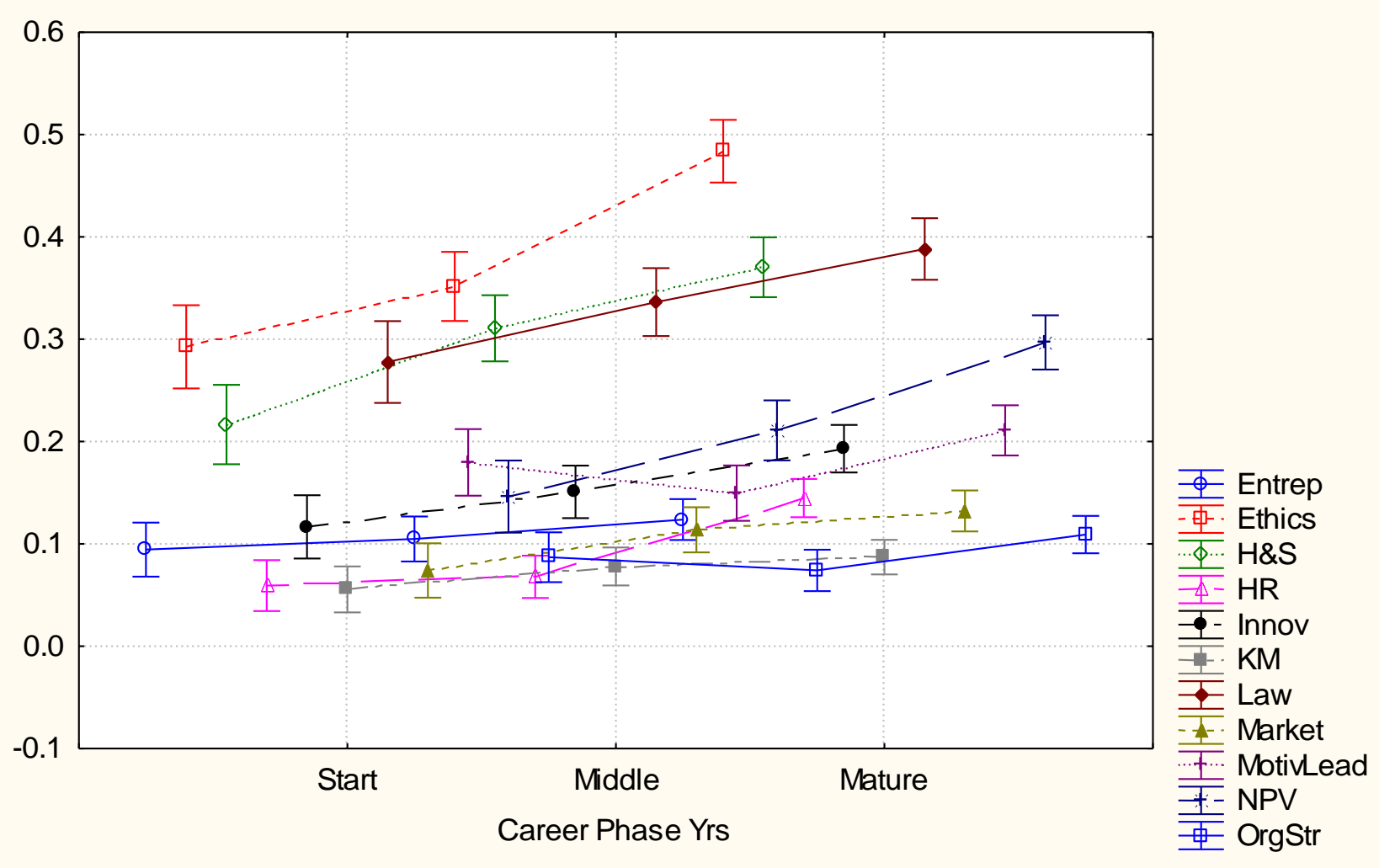


Career Phase Yrs; LS Means

Wilks lambda $=.86863, F(66,4480)=4.9522, p=0.0000$

Effective hypothesis decomposition

Vertical bars denote 0.95 confidence intervals

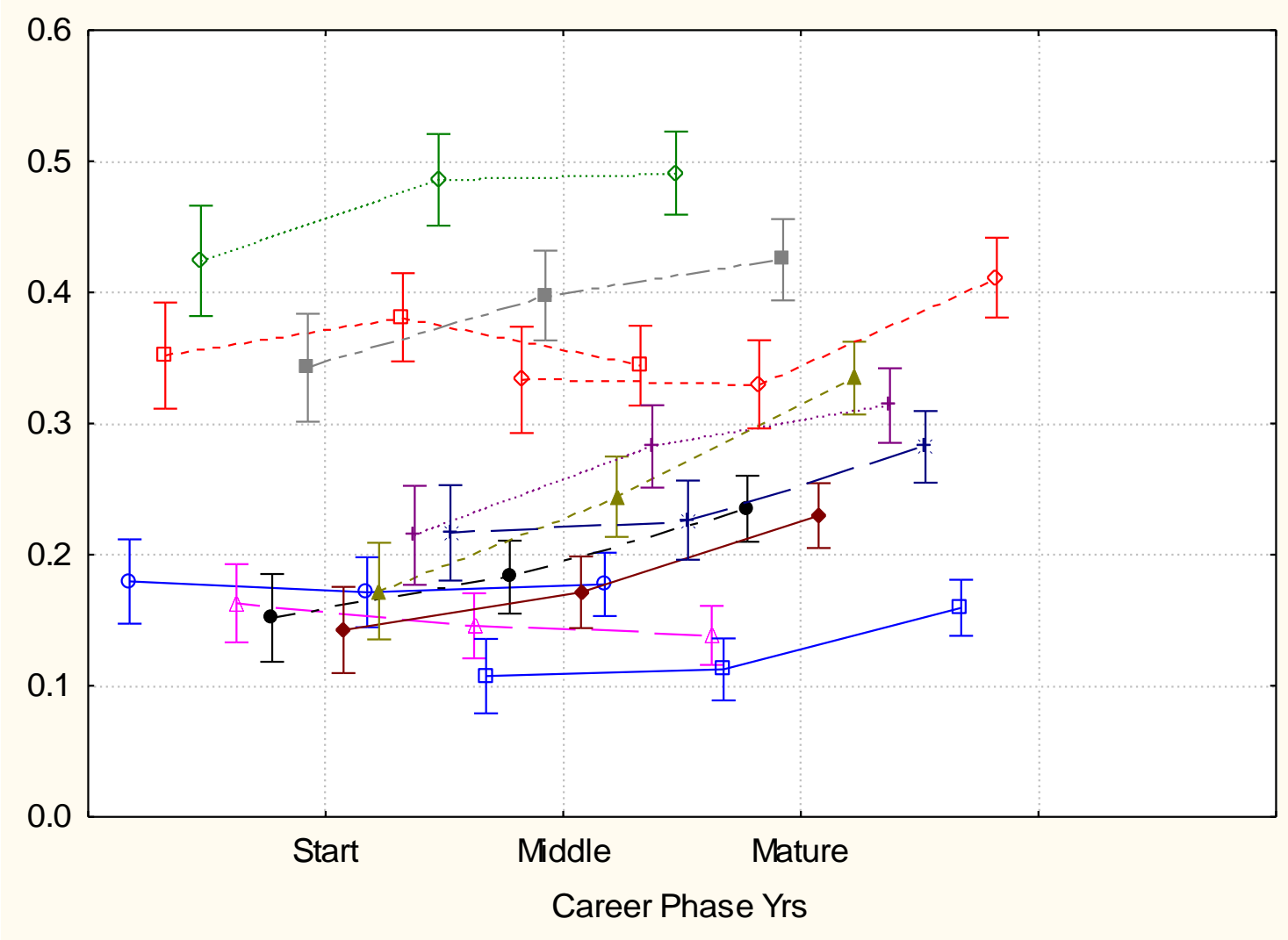

Persnlty
PM_Monit
PM_Plan
ProjCost
Puality
PiskMan
Procure
Enviro
PofMemb
Society
Strategy
. TeamDev 


\section{List of Tables}

Table A1: Available responses to Q18 Survey question.

\begin{tabular}{|c|c|c|}
\hline & Description & Abbreviation \\
\hline 1 & Career planning & CareerPln \\
\hline 2 & Business Processes in typical employer firms & BusProcess \\
\hline 3 & Personality Styles & Persnlty \\
\hline 4 & Development and management of Teams & TeamDev \\
\hline 5 & Motivational Leadership & MotivLead \\
\hline 6 & Professional relationship with society & Society \\
\hline 7 & $\begin{array}{l}\text { Cultural issues including Biculturalism, Multiculturalism and } \\
\text { Treaty. }\end{array}$ & Cultural \\
\hline 8 & Health and safety requirements. & $H \& S$ \\
\hline 9 & Professional associations including IPENZ. & ProfMemb \\
\hline 10 & Ethics. & Ethic \\
\hline 11 & $\begin{array}{l}\text { Environment and Sustainability including Resource } \\
\text { Management Act }\end{array}$ & Enviro \\
\hline 12 & Project planning & PM_Plan \\
\hline 13 & Project monitoring & PM_Monit \\
\hline 14 & Communication including report writing. & Communic \\
\hline 15 & Engineering relevant Finance and project costing methods & ProjCost \\
\hline 16 & Accounting principles & Account \\
\hline 17 & Economics & Econ \\
\hline 18 & Budgets, Profit and Loss Statement & Budget \\
\hline 19 & NPV, Capital, and Depreciation & NPV \\
\hline 20 & Product Life cycle, R\&D stages, Innovation, Creativity & Innov \\
\hline 21 & Risk Management, including SAA/SNZ HB 436 & RiskMan \\
\hline 22 & Change Management & ChangeMan \\
\hline 23 & Engineering relevant law, Contracts, Product liability & Law \\
\hline 24 & Quality, Organisational Systems & Quality \\
\hline 25 & Product certification & PrdCert \\
\hline 26 & Procurement. & Procure \\
\hline 27 & Contract administration. & Contract \\
\hline 28 & Human Resource Management & $H R$ \\
\hline 29 & Organisational Structure & OrgStr \\
\hline 30 & Knowledge Management, NDA, IP Protection & $K M$ \\
\hline 31 & Marketing & Market \\
\hline 32 & Entrepreneurship, organisation formation and growth & Entrep \\
\hline 33 & Strategy, External forces, Mission, Vision, Governance. & Strategy \\
\hline
\end{tabular}


Table C1: Least squares mean importance of each topic, partitioned into career phase.

\begin{tabular}{|l|l|l|l|}
\hline Career Phase Yrs & Start & Middle & Mature \\
\hline Account Mean & 0.127778 & 0.225064 & 0.267576 \\
\hline Budget Mean & 0.196296 & 0.181586 & 0.242392 \\
\hline BusProces Mean & 0.253704 & 0.283887 & 0.339979 \\
\hline CareerPIn Mean & 0.251852 & 0.249361 & 0.218258 \\
\hline ChangeMan Mean & 0.070370 & 0.112532 & 0.135362 \\
\hline Communic Mean & 0.427778 & 0.501279 & 0.514166 \\
\hline Contract Mean & 0.242593 & 0.343990 & 0.378804 \\
\hline Cultural Mean & 0.081481 & 0.104859 & 0.109129 \\
\hline Econ Mean & 0.142593 & 0.148338 & 0.146905 \\
\hline Entrep Mean & 0.094444 & 0.104859 & 0.123820 \\
\hline Enviro Mean & 0.214815 & 0.282609 & 0.313746 \\
\hline Ethics Mean & 0.292593 & 0.351662 & 0.483736 \\
\hline H\&S Mean & 0.216667 & 0.310742 & 0.370409 \\
\hline HR Mean & 0.059259 & 0.067775 & 0.144806 \\
\hline Innov Mean & 0.116667 & 0.150895 & 0.193075 \\
\hline KM Mean & 0.055556 & 0.078005 & 0.087093 \\
\hline Law Mean & 0.277778 & 0.336317 & 0.388248 \\
\hline Market Mean & 0.074074 & 0.113811 & 0.132214 \\
\hline MotivLead Mean & 0.179630 & 0.149616 & 0.210913 \\
\hline NPV Mean & 0.146296 & 0.210997 & 0.296957 \\
\hline OrgStr Mean & 0.087037 & 0.074169 & 0.109129 \\
\hline Persnlty Mean & 0.179630 & 0.171355 & 0.177335 \\
\hline PM_Monit Mean & 0.351852 & 0.381074 & 0.344176 \\
\hline PM_Plan Mean & 0.424074 & 0.485934 & 0.491081 \\
\hline PrdCert Mean & 0.055556 & 0.046036 & 0.037775 \\
\hline Procure Mean & 0.162963 & 0.145780 & 0.138510 \\
\hline ProfMemb Mean & 0.151852 & 0.182864 & 0.235047 \\
\hline ProjCost Mean & 0.342593 & 0.397698 & 0.424974 \\
\hline Quality Mean & 0.142593 & 0.171355 & 0.229801 \\
\hline RiskMan Mean & 0.172222 & 0.244246 & 0.334732 \\
\hline Society Mean & 0.216667 & 0.226343 & 0.282267 \\
\hline Strategy Mean & 0.107407 & 0.112532 & 0.159496 \\
\hline TeamDev Mean & 0.333333 & 0.329923 & 0.411333 \\
\hline N (sample size) & 540 & 782 & 953 \\
\hline & & & \\
\hline
\end{tabular}




\section{Short Abstract (100 words)}

The profession depends on its practitioners developing management and leadership skills to achieve good client outcomes and robust, reliable products or services, delivered by profitable, ethically run engineering businesses. The difficulty is determining what those skills are, and where in the career they are needed. The New Zealand population of professional engineers was surveyed to rate the importance of a list of management and leadership topics. Results show the relative importance of various topics and how their importance is perceived differently with years of experience. The results also help differentiate the roles of teaching institutions and ongoing in-career professional development.

\section{References}

ASME. (2010). Guide to the engineering management body of knowledge. New York: ASME. Balogun, J., \& Hailey, V. (2004). Exploring strategic change. Harlow, England: Prentice Hall. Bandura, A. (1997). Self-efficacy. Harvard Mental Health Letter, 13(9), 4.

Banik, G. (2008). Industry expectations from new construction engineers and managers: Curriculum improvement. Paper presented at the ASEE American Society for Engineering Education, Chantilly, VA 20153, United States.

Baughman, J. A., Brumm, T. J., \& Mickelson, S. K. (2014). Holistic student professional development and assessment: A backward design approach. Journal of Technology, Management, and Applied Engineering, 31(1), 1-13.

Becerra-Fernandez, I., Lee, T., \& Hopkins, G. (1998). Reaching out to engineering management students. Paper presented at the ASEE Conference, Washington, DC, USA.

Beruvides, M. G., \& James, M. R. (1997). Perceptions from the trenches: Engineering management vs. MBA. Paper presented at the ASEE Conference, Washington, DC, USA.

Bowen, D., Ganjeizadah, F., Motavalli, S., \& Zong, H. (2005). Development of a new M.S. Degree in engineering management. Paper presented at the ASEE Conference, Chantilly, VA 20153, United States.

Burnes, B. (2005). Complexity theories and organizational change. International Journal of Management Reviews, 7(2), 73-90.

Cannella Jr, A. A. (2001). Upper echelons: Donald Hambrick on executives and strategy. Academy of Management Executive, 15(3), 36.

Chewning, R. C. (2000). Leadership's Role in Servanthood. Baylor Business Review, 18(1), 15.

Conger, J. A., \& Kanungo, R. N. (1987). Toward a Behavioral Theory of Charismatic Leadership in Organizational Settings. Academy of Management Review, 12(4), 637.

Conger, J. A., \& Kanungo, R. N. (1994). Charismatic leadership in organizations: perceived behavioral attributes and their measurement. Journal of Organizational Behavior, 15(5), 439-452.

Conger, J. A., \& Kanungo, R. N. (1997). Measuring charisma: Dimensionality and validity of the Conger-Kanungo scale of charismatic leadership. Canadian Journal of Administrative Sciences, 14(3), 290.

Conger, J. A., Kanungo, R. N., \& Menon, S. T. (2000). Charismatic leadership and follower effects. Journal of Organizational Behavior, 21(7), 747.

Crippen, C. (2005). Servant-Leadership as an Effective Model for Educational Leadership and Management: first to serve, then to lead. Management in Education, 18(5), 11-16.

Dulewicz, V., \& Higgs, M. (2005). Assessing leadership styles and organisational context. Journal of Managerial Psychology, 20(2), 105-123. DOI: doi:10.1108/02683940510579759

Farr, J. V., \& Bowman, B. A. (1999). ABET accreditation of engineering management programs: contemporary and future issues. Engineering Management Journal, 11(4), 7-13.

Fisher Jr., J. R. (2004). Servant Leadership. Executive Excellence, 21(5), 15-16. 
Furterer, S., Jenness, J., Steinberg, J., Crumpton-Young, L., Williams, K., \& Rabelo, L. (2006). Experiential learning for industrial engineering curriculum. Paper presented at the ASEE Conference, Chantilly, VA 20153, United States.

Giampetro-Meyer, A., Brown, T., Browne, M. N., \& Kubasek, N. (1998). Do We Really Want More Leaders in Business? Journal of Business Ethics, 17(15), 1727-1736.

Giegold, W. C. (1981). LEADERSHIP - THE ESSENTIAL OF ENGINEERING MANAGEMENT. Engineering Management International, 1(1), 49-56.

Graetz, F., Rimmer, M., Lawrence, A., \& Smith, A. (2006). Managing organisational change (2 ed.). Brisbane: John Wiley \& Sons.

Greenleaf, R. K. (2002). Servant Leadership: A Journey into the Nature of Legitimate Power and Greatness. New Jersey: Paulist Press.

Horwitch, M., \& Stohr, E. A. (2012). Transforming technology management education: Value creation-learning in the early twenty-first century. Journal of Engineering and Technology Management - JET-M, 29(4), 489-507. DOI: 10.1016/j.jengtecman.2012.07.003

IEM. (2009). Graduate Attributes and Professional Competencies. Version 2 - 18 June 2009. Retrieved 23 Nov 2009, from http://www.washingtonaccord.org/IEA-Grad-Attr-ProfCompetencies-v2.pdf

IPENZ. (2009). Continuing professional development good practice guidelines Retrieved 12 June 2009, from

http://www.ipenz.org.nz/ipenz/members/cpdsummary/documents/GoodPracticeGuidelines . $\mathrm{pdf}$

IPENZ. (2015). Fields of Engineering. Institution of Professional Engineers New Zealand, http://www.ipenz.org.nz/IPENZ/Engineering Practice/Fields of engineering.cfm\#Managem ent(last accessed 10 June 2015)).

Johnson, G., \& Scholes, K. (2002). Exploring corporate strategy (Sixth ed.). Harlow: Pearson Education Ltd (Financial Times Prentice Hill).

Joshi, G. (2004). Development of engineering management course at southern university. Paper presented at the ASEE Annual Conference, Washington, DC 20036, United States.

Kaplan, R. S., \& Norton, D. P. (1992). The Balanced Scorecard--Measures That Drive Performance. Harvard Business Review, 70(1), 71-79.

Ladd, E. R., Holt, J. R., \& Rumsey, H. A. (2001). The engineering management program at Washington state university: Distance education industry partnership success stories. Paper presented at the ASEE Annual Conference, Washington, DC 20036, United States.

Lewis Jr, V. W., \& Kauffmann, P. (2002). Enhancement of a civil engineering technology curriculum by the addition of a minor in engineering management. Paper presented at the ASEE Annual Conference, Washington, DC 20036, United States.

Mallick, D. N., \& Chaudhury, A. (2000). Technology management education in MBA programs: A comparative study of knowledge and skill requirements. Journal of Engineering and Technology Management - JET-M, 17(2), 153-173.

Merino, D. N. (2000a). Executive level masters programs in technology management (TM), management of technology (MOT) and engineering management (EM). Paper presented at the ASEE Annual Conference, Washington, DC 20036, United States.

Merino, D. N. (2000b). Impact of ABET 2000 on teaching engineering economics: What subjects define economic literacy for engineers? Paper presented at the ASEE Annual Conference, Washington, DC 20036, United States.

Meyers, F. D., Fentiman, A. W., \& Britton, R. R. (1993). The engineering core courses: are they preparing students for the future? Paper presented at the First International Conference on Graphics Education, Lisbon, Portugal.

Mingers, J. (1991). Content of MSc Operational Research courses. Results of a questionnaire to OR groups. Journal of the Operational Research Society, 42(5), 375-382. 
NIST. (2013). Criteria for performance excellence, Baldrige National Quality Progam. Retrieved 15 November 2013, from http://www.nist.gov/baldrige/

Pons, D. J., \& Raine, J. (2014). Engineering management in professional practice. IPENZ Transactions, 41, 1-10. DOI: http://www.ipenz.org.nz/ipenz/forms/pdfs/IPENZTransactions41EngineeringManagementinPractice.pdf?61255

Raine, J. K. (1996, July 4-5). Undergraduate management teaching in mechanical engineering at the University of Canterbury. Paper presented at the Proceedings of Fifth Annual Engineering Management Educators Conference, "Shaping the Future of Engineering Management Education", Australian Graduate School of Engineering Innovation, Sydney.

Robbins, S. P., Millett, B., Cacioppe, R., \& Waters-Marsh, T. (2001). Organisational behaviour: leading and managing in Australia and New Zealand (3 ed.). Frenchs Forest NSW, AU: Prentice Hall.

Simonet, D. V., \& Tett, R. P. (2013). Five Perspectives on the Leadership-Management Relationship: A Competency-Based Evaluation and Integration. Journal of Leadership \& Organizational Studies, 20(2), 199-213. DOI: 10.1177/1548051812467205

Sun, H., Yam, R. C. M., \& Venuvinod, P. K. (1999). Education in engineering management. Journal of Engineering Education, 88(2), 181-184.

Waks, S., \& Frank, M. (2000). Engineering curriculum versus industry needs-a case study. IEEE Transactions on Education, 43(3), 349-352.

Williamson, J. M., Lounsbury, J. W., \& Han, L. D. (2013). Key personality traits of engineers for innovation and technology development. Journal of Engineering and Technology Management - JET-M, 30(2), 157-168. DOI: 10.1016/j.jengtecman.2013.01.003 